\title{
$\begin{array}{r}\text { WAGENINGEN } \\ \text { UNIVERSITY \& RESEARCH } \\ \hline\end{array}$
}

\section{Early-season crop colonization by parasitoids is associated with native vegetation, but is spatially and temporally erratic}

Bianchi, F. J. J. A., Walters, B. J., Hove, A. L. T., Cunningham, S. A., van der Werf, W., Douma, J. C., \& Schellhorn, N. A.

This is a "Post-Print" accepted manuscript, which has been published in "Agriculture, Ecosystems and Environment"

This version is distributed under a non-commercial no derivatives Creative Commons (C) $(1) \Theta$ reproduction in any medium, provided the original work is properly cited and not used for commercial purposes. Further, the restriction applies that if you remix, transform, or build upon the material, you may not distribute the modified material.

Please cite this publication as follows:

Bianchi, F. J. J. A., Walters, B. J., Hove, A. L. T., Cunningham, S. A., van der Werf, W., Douma, J. C., \& Schellhorn, N. A. (2015). Early-season crop colonization by parasitoids is associated with native vegetation, but is spatially and temporally erratic. Agriculture, Ecosystems and Environment, 207, 10-16. https://doi.org/10.1016/j.agee.2015.03.018 
1 Early-season crop colonization by parasitoids is associated with native vegetation, but is

2 spatially and temporally erratic

3

4 F.J.J.A.Bianchi ${ }^{1,2,3}$, B.J. Walters ${ }^{1,2}$, A.L.T. ten Hove $^{3}$, S.A. Cunningham ${ }^{2,5}$, W. van der Werf ${ }^{4}$, 5 J.C. Douma ${ }^{4}$, and N.A. Schellhorn ${ }^{1,2}$

6

$7 \quad{ }^{1}$ CSIRO Agriculture Flagship, P.O. Box 2583, Brisbane, QLD 4001, Australia

$8 \quad{ }^{2}$ Cotton Catchment Communities CRC, Australian Cotton Research Institute, Narrabri, NSW

9 2390, Australia

$10{ }^{3}$ Farming Systems Ecology, Wageningen University, P.O. Box 563, 6700 AN Wageningen,

11 The Netherlands

$12{ }^{4}$ Crop and Weed Ecology Group, Centre for Crop Systems Analysis, PO Box 430, 6700 AK

13 Wageningen, The Netherlands

$14{ }^{5}$ CSIRO Agriculture Flagship, P.O. Box 1700, Canberra, ACT 2601, Australia

15

16 Correspondance:

$17 \quad$ F.J.J.A. Bianchi

18 Wageningen University

19 Farming Systems Ecology

20 P.O. Box 563,

216700 AN Wageningen,

22 The Netherlands

23 Email: felix.bianchi@wur.nl

24 Tel: + 3131781197

25 
27 Semi-natural habitats in agricultural landscapes may support parasitoid populations that

28 provide biocontrol services by suppressing populations of crop pests, but little is known about

29 the spatial pattern and variability of these services at different levels of scale. Here we

30 investigate the rarely studied phenomenon of early-season crop colonization by parasitoids

31 and the relationship with the surrounding landscape. We assessed parasitism of whiteflies by

32 placing whitefly infested cotton seedlings in remnant vegetation, arable land 25-125 m from

33 remnant vegetation, and arable land further than $400 \mathrm{~m}$ from remnant vegetation. Twelve to

34 twenty sentinel plants were exposed in a 25 x 25 m grid pattern in plots in each habitat. The

35 experiment was conducted at 18 locations across two landscapes and repeated three times in a

36 2-week period in 2007 and 2008. Parasitism was observed during the first three days after the

37 introduction of the whitefly infested seedlings and was in all cases caused by Encarsia spp.

38 The mean number of parasitized whitefly per plant was $0.106 \pm 0.025$ and was highest on

39 cotton plants placed in remnant vegetation, declining with increasing distance from remnant

40 vegetation. A regression model with land use and meteorological variables received more

41 statistical support from the data than models with only landscape and time period as factors.

42 Parasitism levels were influenced by the proportion of remnant vegetation, grassland, as well

43 as wind, temperature, dew point temperature and year. Early-season colonization of whitefly

44 infested seedlings by parasitoids was erratic and characterized by large spatial (inter-plant and

45 inter-plot) and temporal variation. Our study confirms that remnant vegetation function as

46 reservoirs for parasitoids and that parasitoids can penetrate arable fields beyond $125 \mathrm{~m}$ within

473 days. However, variation in the occurrence of parasitism makes it difficult to predict

48 parasitoid colonisation at a specific place and time. Therefore, field-based scouting for pests

49 and parasitoids is necessary, even in landscapes with a high biocontrol potential.

50

51 
Highlights:

53

54

55

56

57

58 Keywords: parasitism, spatial ecology, biological control, whitefly, Encarsia, ecosystem

59 service

- The rate of crop colonization from remnant vegetation exceeds $125 \mathrm{~m}$ in three days

- There is on average a clear effect of landscape variables on parasitism rates

- Land use and meteorological variables explain parasitism rates

- There is low predictability of parasitism at a specific place and time 
61 With increasing concern that biocontrol services are declining at a world-wide scale

62 (Millennium Ecosystem Assessment 2005) there is growing interest in habitat management to restore functional biodiversity in agricultural landscapes and strengthen natural biocontrol potential (Gurr et al. 2012). Despite growing consensus that landscape heterogeneity can support arthropod mediated biocontrol services in crops (Bianchi et al. 2006, Chaplin-Kramer et al. 2011), there are many questions regarding the spatial pattern of these ecosystem services around resource habitats of the natural enemies, and the distances over which these services extend into crops (Kremen 2005, Schellhorn et al. 2008). Identifying the appropriate management scales for conservation biological control requires understanding of how landscape heterogeneity influences the processes underlying natural pest control, including the frequency and spatial extent of dispersal of biological control agents from source habitats to crops and the associated variability in time and space. While the importance of native perennial vegetation for sustaining parasitoid populations and crop colonization has been demonstrated (Landis and Haas 1992, Dyer and Landis 1997, Bianchi et al. 2008, Thomson and Hoffmann 2009, Letourneau et al. 2012, Macfadyen and Muller 2013), the spatial and temporal variation associated with the crop colonization process and how this is influenced by the surrounding landscape has largely been overlooked. Information on the predictability of the crop colonization process by natural enemies is essential to inform effective conservation biological control programs that aim to strengthen biocontrol services by habitat management. Despite growing concerns about the sustainability of pest management strategies based on the use of synthetic insecticides, these chemicals provide short term pest control that is highly predictable, which makes them attractive pest management option for conventional farmers (Ekström and Ekbom 2011) even where there is a longer term risk of pest resistance. The predictability of natural biocontrol differs fundamentally from that of synthetic insecticides as it depends on the colonization of natural enemies from habitats outside the field into the target crop (Wissinger 1997, Schellhorn et al. 2014). This process depends on 
turn can be influenced by the quality and spatial distribution of source habitats in the surrounding landscape from which natural enemies are recruited and weather conditions favouring or discouraging dispersal. The dispersal-driven colonization process is therefore a variability generating process, and underlies the intrinsically stochastic nature of biocontrol as compared to the use of synthetic insecticides.

The predictability of benefits from non-crop habitats could be improved when biocontrol agents have large dispersal capacity and if different habitat patches have overlapping areas of influence, providing spatial insurance in the case that a particular habitat patch would not provide natural enemies (Loreau et al. 2003). While the dispersal capacity of marked parasitoids are typically assessed at spatial scales less than $100 \mathrm{~m}$ (Schellhorn et al. 2014), one of the few studies that quantified parasitoid dispersal over larger distances indicates that the emergent spatial pattern is erratic (Kristensen et al. 2013). Estimates of the dispersal capacity of parasitoids can also be derived from spatially-indexed regression approaches, which suggest that crop colonization from source habitats can take place over distances of 1-1.5 km and further (Thies et al. 2003, Bianchi et al. 2008), but these studies do not always differentiate between the colonization process and local reproduction at target sites (e.g., Thies et al. 2003). There is a need for further studies to underpin our understanding of the initial crop colonization by parasitoids that capture the appropriate spatial and temporal scales and provide information on the biotic and abiotic factors influencing the colonization process.

Australia hosts many indigenous whitefly species (Martin 1999, De Barro et al. 2000, Sequeira et al. 2009), but these are typically not considered agricultural pests. In 1994, the major pest Bemisia tabaci (Middle East - Asia Minor 1 (MEAM1)) arrived in Australia (De Barro et al. 2011), which now causes economic damage to melons, cotton, and soybean. Whiteflies are attacked by indigenous and exotic aphelinid parasitoids (De Barro et al. 2000). In cotton, parasitism of B. tabaci MEAM1 nymphs by Eretmocerus and Encarsia spp. is highly variable, and can be as high as $80 \%$ depending on time of year, pest management, and host density (Sequeira et al. 2009). 
The 2-year study reported here focuses on the colonization of whitefly parasitoids

117 early in the growing season as this period is considered critical for effective suppression of

118 pest populations that have potential for exponential increase (Schellhorn et al. 2014). The aim

119 of the study is twofold. Firstly, to assess the factors that best explain the colonization of

120 parasitoids for plots in, near to and further than $400 \mathrm{~m}$ from remnant vegetation. Secondly, to

121 assess the variability of biocontrol services associated with remnant vegetation by comparing

122 the colonization in plots of remnant vegetation and plots in arable fields near and further away

123 from remnant vegetation. Variability is assessed at two spatial scales (plant and plot level)

124 and between time periods.

125

126 Materials and Methods

127

128 Study sites

129 The study was conducted at 18 locations spread among two $5 \mathrm{~km}$ radius landscape sectors in

130 an arable production area west of the Great Dividing Range, near Dalby, Queensland,

131 Australia. The areas were 50 km apart, with the centres located at 151 6' 2.28" E; 26 51'

132 31.52" S (North landscape) and 151 5' 47.83" E; 27 17' 43.43" S (South landscape). The

133 landscapes consisted of agricultural fields, including sorghum (Sorghum bicolor L. Moench),

134 barley (Hordeum vulgare L.), canary (Phalaris canariensis L.), chick pea (Cicer arietinum

135 L.), mungbean (Vigna radiata L.), oat (Avena sativa L.), wheat (Triticum aestivum L.) and

136 cotton (Gossypium hirsutum L.), as well as grassland, and remnant native vegetation in

137 various forms (linear strips of trees, patches of remnant vegetation and remnant vegetation

138 along creeks). The plant species composition of the remnant vegetation was similar in both

139 landscapes. Remnant vegetation was dominated by Eucalyptus populnea (F. Muell.), Acacia

140 salicina (Lindl.) and A. harpophylla (F. Muell.) in the tree and shrub layer, and several

141 chenopodiaceous species in the understory (Bianchi et al. 2012). 
144 Experiments were conducted in the spring (October) of 2007 and 2008, around the time at

145 which the first cotton is sown and colonization by cotton herbivores and their natural enemies

146 begins. In each landscape, 3 plots (75 m x $50 \mathrm{~m}$ ) were laid out in patches of remnant

147 vegetation, 3 plots (75 m x $100 \mathrm{~m}$ ), within in arable fields at $25 \mathrm{~m}$ from the edge of the

148 remnant vegetation plots, and 3 plots $(75 \mathrm{~m} \mathrm{x} 100 \mathrm{~m})$ in arable fields with the nearest edge at

149 least $400 \mathrm{~m}$ from remnant vegetation, for a total of 18 plots (2 landscapes x 9 plots) in each

150 year (Fig. 1). We refer to the location of the plots (i.e. within, near and far from remnant

151 vegetation) as “treatment”. In 2007, all arable fields were fallow, containing sorghum or

152 cereal stubble, whereas in 2008, which was wetter than 2007, most fallow fields were planted

153 and therefore plots were established in newly planted sorghum fields. At the start of the

154 experiment sorghum plants were $13.6 \pm 1.56 \mathrm{~cm}$ high (mean $\pm \mathrm{SEM}$ ). Twelve sentinel cotton

155 plants ( 3 x 4) were placed in a $25 \times 25$ m grid pattern in each remnant vegetation plot (plot

156 size $50 \times 75$ m), while twenty sentinels ( 5 x 4) were placed in each of the arable plots (near

157 and far; plot size 100 x 75 m) (Fig. 1). By placing these cotton seedlings in fallow (2007) or

158 newly sown fields (2008) we mimicked an emerging cotton crop, and avoided potential

159 confounding effects of parasitism from within the field versus the surrounding landscape. In

160 both years, seedlings were set out and recollected three times in each plot within a time

161 window of approximately two weeks coinciding with the time of emergence of the cotton. In

162 each landscape we took half-hourly records of temperature, precipitation, wind, and dewpoint

163 temperature, using a Davis Vantage Pro2 weather station (South Windsor, Australia). In

164 summary, the design included 108 plots with 1872 plants: 3 treatments (within + near + far $=$

$16512+20+20=52$ plants $) \times 3$ spatial replicates $\times 2$ landscapes $\times 3$ periods $\times 2$ years.

166 Sentinel cotton seedlings were grown in pots (8 cm diameter, $7 \mathrm{~cm}$ high) and brought

167 into the field when they were five weeks old (height 6-10 cm, 2-4 leaf stage). The seedlings

168 were infested with silverleaf whitefly eggs two weeks prior to exposure to ensure that nymphs

169 were in the second/third instar during exposure, which is the preferred stage for parasitism by

170 Eretmocerus and Encarsia spp. Whitefly density typically ranged between 50 and 150

171 nymphs per plant. The seedlings were put in trays which were secured to the ground. The 
cotton seedlings were collected after approximately three days exposure in the field, covered with polypropylene nets to prevent further parasitism, and returned to the laboratory to score parasitism rate and rear out and identify parasitoids. Once the nymphs reached the 'redeye' stage the seedlings were cut and put individually in polypropylene bags with an emergence cup in one corner of the bag. The bags were placed in cardboard boxes with cups protruding out the top, such that whiteflies and parasitoids were reared out and emerged individuals were self-collecting in the cups due to positive phototaxis and negative geotaxis responses. After six weeks the whiteflies and parasitoids were counted and identified.

Land use around each plot was assessed by quantifying the areas of woody remnant vegetation, grassland, sorghum, barley, canary, chick pea, mungbean, oat, wheat and cotton (in ha) at scales of 0-100, 100-500, 500-1000, 1000-1500 and 1500-2000 m using ground survey and ArcGIS.

\section{Data analysis}

The final dataset contained observations of parasitism rates from 1698 plants. Data were missing from 9 plants due to vertebrate grazing, while no whiteflies or parasitoids were found in the rearing bags from 165 plants, indicating a problem during rearing out (e.g. inability to move through the bag towards the light). These missing data were randomly distributed across the plots and were therefore discarded from the analysis.

Parasitism was analysed as count data (i.e. the number of parasitoids emerged per whitefly infested seedling) because the proportion parasitized whiteflies was very low for the great majority of samples (mean parasitism rate was $0.39 \%$, and $98.3 \%$ of the parasitism rates were below 5\%), indicating a practically unlimited host resource. Four discrete stochastic distributions were considered for the error distribution of the data: Poisson, negative binominal, zero-inflated Poisson and zero-inflated negative binominal. A log-link was used for all models such that the response variable is related to the linear regression via:

$$
Y \sim \operatorname{Poisson}\left(\lambda=e^{\left(\beta_{0}+\beta_{1} \cdot X_{1}+\beta_{2} \cdot X_{2}+\cdots\right)}\right)
$$




$$
Y \sim N e g \operatorname{Bin}\left(\mu=e^{\left(\beta_{0}+\beta_{1} \cdot X_{1}+\beta_{2} \cdot X_{2}+\cdots\right)}, k\right)
$$

198 The expectation $(\lambda$ and $\mu$ ) was explained by the experimental variables, whereas the error 199 term accounts for the variation in the observations as compared to the expected value. The 200 zero-inflation factor of the zero-inflated distributions and the overdispersion parameter $k$ of 201 the negative binominal distribution were assumed equal across treatments to avoid 202 overparameterization. The models were fitted using glm (for Poisson distribution), glm.nb 203 (for negative binominal distribution) and zeroinfl functions (for zero inflates Poisson and 204 negative binominal distributions) using the R packages MASS (Venables and Ripley 2002) 205 and PSCL (http://cran.r-project.org/web/packages/pscl/pscl.pdf).

206 Akaike’s Information Criterion, corrected for finite sample sizes $\left(\mathrm{AIC}_{\mathrm{c}}\right)$, was used to 207 rank and select models (Burnham and Anderson 2002). As the negative binominal distribution 208 gave a better fit than the other distributions, this distribution was used for all subsequent 209 analyses. The negative binomial distribution is characterized by two parameters: the mean $\mu$ 210 and overdispersion parameter $k$, whereby low values of $k$ (e.g. $k<\mu$ ) reflect overdispersion 211 and high values of $k$ low or no overdispersion. For values of $k>10 \mu$ the negative binomial 212 distribution approaches the Poisson distribution (Bolker 2008). Model selection of 213 explanatory variables was conducted using the dredge procedure in R package MuMIN 214 (http://cran.r-project.org/web/packages/MuMIn/MuMIn.pdf). This procedure generates a 215 complete set of sub-models with combinations of the terms of the full model, and sorts the 216 sub-models on the basis of $\mathrm{AIC}_{\mathrm{c}}$ values and associated Akaike weights. This procedure 217 typically resulted in the same optimal model as the automated model selection process 218 stepAIC of the R package MASS, but has the advantage that a set of models receiving support 219 from the data are identified, rather than a single "best” model.

220 We conducted three different analyses with our data. In the first analysis we 221 considered plant level data and experimental variables, which were used in the experimental 222 design: treatment, landscape, year and period. These factorial explanatory variables account 223 for variation in the biophysical system that drive the colonization process of parasitoids, but 
do not capture information on the nature of the underlying biophysical variables. Two-way

225 interactions between treatment and landscape, and year and period were also considered. To

226 account for differences in the exposure time of sentinels in the field we included the log-

227 transformed exposure hours as an offset variable in the full model (Zuur et al. 2009). In

228 biological terms this means that the response variable is now expressed as the number of

229 parasitoids per unit of time.

230 In a second analysis at the plant level a set of biologically meaningful variables were

231 used to acquire further insight in the biophysical factors driving whitefly parasitism. Land use

232 variables at five spatial scales were used to replace the factors "treatment" and "landscape”.

233 In addition, meteorological variables were used to replace the factors "year" and "period”.

234 The variable "rain” was discarded from the analysis because there was no precipitation during

235 the exposures. The variable "year" was also included as this accounts for any effects of year,

236 e.g. meteorological conditions in the period before exposure and the different vegetation

237 background in plots in arable fields (fallow vs. sorghum seedlings). Hours of exposure (log-

238 transformed) was included as an offset variable in the global model, and no interactions

239 between variables were included.

240 Finally, in a third analysis we tested the association between parasitism in plots in

241 remnant vegetation and plots near or far in arable fields using contingency tables and $\chi^{2}$ test of

242 independence. For this analysis we used presence/absence data at the plot level (Appendix 1).

243 As there were 3 spatial replicates $\times 2$ landscapes $\times 3$ periods $\times 2$ years, we considered a total

244 of 36 cases for each treatment, and expected frequencies were compared to a $\chi^{2}$ test statistic

245 with one degree of freedom using the chisq.test procedure with Yates' continuity correction in

246 R (Crawley 2007). Separate analyses were conducted for the association of parasitism in and

247 near remnant vegetation, and in and far from remnant vegetation.

\section{Results}

250 In 2007 and 2008, 31,724 and 14,803 whiteflies were recovered and 147 and 33 parasitoids,

251 respectively. The average parasitism rates in the 3-day window of exposure were thus $0.46 \%$ 
and $0.22 \%$. All parasitoids were Encarsia spp. The overall mean number of whiteflies emerging per cotton plant was $27.4 \pm 0.64$ (range 0 -177), whereas the overall mean number of emerging parasitoids was $0.106 \pm 0.025$ per plant (range $0-23$ ). Parasitism was observed on 45 out of 1698 plants. The total number of parasitoids from plots in, near and far from remnant vegetation was 119, 59 and 2, respectively (Appendix 2) and was influenced by the variables of the experimental design (Fig. 2). At the within-plot level for plots near remnant vegetation the total number of parasitoids encountered showed a declining trend with increasing distance from remnant vegetation with values of 15 at $25 \mathrm{~m}, 25$ at $50 \mathrm{~m}, 4$ at $75 \mathrm{~m}$, 8 at $100 \mathrm{~m}$, and 7 at $125 \mathrm{~m}$. The model selection procedure of the first analysis considered variables of the experimental design. The factors "treatment” and "year" were included in all six models that received substantial support from the data $\left(\Delta \mathrm{AIC}_{\mathrm{c}}=6\right.$; Table 1$)$. The most parsimonious model received an Akaike weight of 0.385 and contained main effects “treatment”, “period”, “year”, and the "period:year" interaction, and had a negative binomial error distribution with an overdispersion factor $k$ of 0.0217 (Table 2). The model indicated that the number of parasitized whiteflies decreased with increasing distance from natural vegetation, and that the number of parasitized whiteflies in the first period in 2008 were higher than in 2007, but lower in the second and third period. In the second analysis, the variables "treatment”, “landscape”, and “period” were

271 replaced by land use and meteorological data. This resulted in models with more support from 272 the data than the first analysis, reflected by a substantial drop in $\mathrm{AIC}_{\mathrm{c}}$ values (Table $3 \mathrm{vs.}$

273 Table 1). The best models all included the variables area of remnant vegetation, area of 274 grassland, wind, dew point and year $\left(\Delta \mathrm{AIC}_{\mathrm{c}}=6\right.$; Table 3$)$. The most parsimonious model 275 (Akaike weight 0.328) included all these factors and had a negative binomial error distribution with a $k$ of 0.0499 (Table 4). The $k$ value of 0.0499 indicates that this model 277 explains the data better (i.e. the data becomes more Poisson distributed) than the model based 278 on the experimental design resulting from the first analysis $(k=0.0217)$, with a greater part of 279 the variability captured by explanatory variables and with lower residual variation. The 
model indicates that remnant vegetation at 0-100 m, 100-500 and 500-1000 m had a positive

281 effect on the number of parasitoids per plant, whereas remnant vegetation at 1000-1500 m and

282 grassland at 100-500 m had a negative effect. The model also indicated that parasitism

283 increased as wind speed and dew point increased. Furthermore, parasitism decreased with

284 temperature, and was higher in 2007 than in 2008.

The third analysis focussed on presence or absence of parasitism at the plot scale. It

286 showed that parasitism was detected in, near, and far from remnant vegetation in 13 (36.1\%),

$2875(13.9 \%)$ and 2 times (5.6\%) out of the 36 cases, respectively. There were 3 cases where

288 parasitism was observed in plots in remnant vegetation and nearby arable fields in the same

289 period (Appendix 1). The null-hypothesis that presence of parasitism in plots in and near

290 remnant vegetation is independent was not rejected $\left(\chi^{2}=0.486, \mathrm{df}=1, \mathrm{P}=0.486\right)$, indicating a

291 lack of association between incidence of parasitism in remnant vegetation and in nearby plots

292 in arable fields. There was one case when parasitism in remnant vegetation coincided with

293 parasitism in plants $400 \mathrm{~m}$ from remnant vegetation, but also in this case there was no support

294 for the hypothesis that the incidence of parasitism in plots in and far from remnant vegetation

295 are dependent $\left(\chi^{2}=0, \mathrm{df}=1, \mathrm{P}=1\right)$.

\section{Discussion}

298 The main finding of this study is that early-season crop colonization by Encarsia parasitoids

299 is associated with remnant vegetation, but that early-season crop colonization is an infrequent

300 event, resulting in an erratic spatio-temporal pattern that is difficult to predict. Hence, while

301 on average there is a clear effect of landscape variables on parasitism, we also show that there

302 is major variability and hence low predictability of the response at a specific place and time.

303 At the plant level, the variation in the probability of colonization is reflected in the low values

304 of the overdispersion factor $k$ of the negative binomial distribution $(0.0217$ and 0.0499 ,

305 respectively). As these $k$ values are well below the mean value of the number of parasitized

306 whiteflies per plant of 0.106 , the probability density functions have a high probability of zeros

307 and a long tail (i.e. a relatively high probability of having a high number of parasitized 
308 whiteflies per plant). In addition, the variable nature of the crop colonization process by

309 parasitoids at the plot level is illustrated by the limited number of occasions that parasitism in

310 remnant vegetation coincided with parasitism in the adjacent plots, and the fact that parasitism

311 in plots near and far from remnant vegetation were never observed in two sequential periods.

312 Our study thus shows that the spatial pattern of crop colonization by parasitoids from source

313 habitats early in the growing season is heterogeneous, which contrasts with the more even

314 colonization patterns of arable fields by ground-dwelling predators from field edges (e.g.,

315 Thomas et al. 1991). The high level of variability makes predicting the spatial distribution of

316 biocontrol services by parasitoids around source habitats early in the growing season

317 challenging. The difficulty of predicting parasitism events in this context is intrinsically

318 related to the low frequency of parasitism; it is impossible to predict a stochastic event that

319 has a low frequency of occurrence at small temporal or spatial scales.

While crop colonization by parasitoids is intermittent at a temporal scale of several

321 days, there are examples of effective pest suppression mediated by natural enemies that

322 sporadically visit pest-infested plants early in the growing season (Costamagna and Landis

323 2007). In particular ladybeetles are considered beneficial because they increase their aphid

324 intake at higher aphid densities (Costamagna and Landis 2007). However, the role of

325 parasitoids in early-season pest suppression is less well documented. Our data indicate that

326 Encarsia parasitoids can penetrate arable fields and parasitize whiteflies at distances beyond

$327125 \mathrm{~m}$ from their source habitats in approximately three days, and occasionally reaching up to

$328400 \mathrm{~m}$. This is a substantially higher dispersal capacity than found for Encarsia inaron in an

329 orchard, which only moved up to $30 \mathrm{~m}$ in a 2-week period (Pickett and Pitcairn 1999).

330 Although the rate of parasitism detected was low in our experiment, it is important to consider

331 that we focused only on the colonization stage, so the significance for pest suppression could

332 still be great. Early-season parasitism in crops is likely to result in effective pest suppression

333 because there is more time available for the parasitoid population to build-up before pests

334 reach economic damage thresholds (Rauwald and Ives 2001). 
The colonization rates of crops by parasitoids were quantified at the plant and plot

336 scale $(100 \times 75 \mathrm{~m})$ and appeared scale dependent. For arable fields near remnant vegetation,

337 the probability of parasitism was $4.8 \%$ at the plant scale and $13.9 \%$ at the plot scale, while for

338 fields far from remnant vegetation this was 0.04 and 5.6\%, respectively. These contrasting

339 findings between plant and plot scale prompt the question "what is the most relevant spatial

340 scale of crop colonization for biocontrol?” For Encarsia parasitoids, which can have multiple

341 generations within the growing season of a cotton crop, the plot scale is likely more relevant

342 provided that the progeny of the colonizing parasitoid population remains in the crop and

343 continue parasitizing hosts. Under favourable conditions even a few founding female

344 parasitoids could establish an effective population of parasitoids and influence the biocontrol

345 outcome in a growing season. In addition, because the trials lasted approximately 3 days, it

346 could well be the case that we have documented a series of snapshots of a continuous

347 colonization process taking place over longer time scales. This would suggest that fields that

348 were not colonized by parasitoids during the exposure periods, might nevertheless have been

349 colonized at a later stage.

350 Despite intensive sampling we observed parasitism in remnant vegetation plots in

351 only 13 out of 36 cases, indicating that the spatial distribution of parasitoid populations within

352 remnant vegetation is scattered. Assessment of the arthropod community on the dominant

353 plant species in these plots (Eucalyptus, Acacia and Chenopodium spp.) showed no adult

354 whiteflies, which suggests that these species are not a source of alternative hosts for

355 parasitoids of whiteflies (Bianchi et al. 2012). However, less prevalent plant species that were

356 not included in the vegetation assessment could have supported whiteflies. Although our

357 experiment does not irrefutably demonstrate that remnant vegetation was the source of the

358 parasitoids found in the arable fields, it is very likely that the parasitoids that colonized the

359 sentinel plants in arable fields originated from locations outside these fields because fallow

360 and sorghum seedlings (the only other local habitats) do not support whiteflies and their

361 parasitoids. The relatively high levels of parasitism in remnant vegetation in combination with

362 observations that parasitoids move from remnant vegetation into crops early in the season 
(Dyer and Landis 1997, Macfadyen and Muller 2013) provide circumstantial support that

364 remnant vegetation is a source habitat for parasitoids. Ironically, based on the $\chi^{2}$ test of

365 independence there was no statistical support for the hypothesis that presence of parasitism in

366 remnant vegetation plots was associated with parasitism in nearby arable fields. Further

367 research on the spatial distribution of parasitoids in remnant vegetation patches and the crop

368 colonization process is needed to resolve this apparent paradox.

369 The second analysis of whitefly parasitism by Encarsia at the plant level showed the

370 importance of remnant vegetation at different scales. The effects of woody remnant

371 vegetation at $0-100,100-500$ and $500-1000 \mathrm{~m}$ on parasitism were all positive. However, the

372 effect of woody remnant vegetation at 1000-1500 m was negative. As the woody remnant

373 vegetation at 1000-1500 m was correlated with the factor landscape (Pearson-correlation

374 coefficient of 0.60 ), this result may have accounted for the fact that parasitism in the

375 landscape with $13 \%$ remnant vegetation (at a scale of $5 \mathrm{~km}$ radius) was lower than in the

376 landscape with 6\% remnant vegetation. In addition, the area of grassland (at two spatial

377 scales), wind, temperature, dew point and year were also selected as explanatory variables in

378 the most parsimonious model (Table 4). The role of grassland for whitefly-Encarsia

379 interactions is unknown, but possibly these habitats provided host plants for whitefly and

380 Encarsia. Nevertheless, since this variable had opposing signs for 100-500 and 500-1000 m,

381 we cannot be certain of the ecological function of grassland for whitefly parasitoids. Wind

382 had a positive effect on the parasitism rates. Although parasitoids typically do not fly under

383 windy conditions as it may hinder directed flight (Fink and Volkl 1995), strong winds may

384 also result in occasional undirected redistribution of parasitoids over larger distances. This

385 conjecture could explain the few cases that parasitism was observed in plots further than 400

$386 \mathrm{~m}$ from remnant vegetation. Temperature had a negative effect on parasitism. Given the

387 relative high day temperatures with some recorded maxima above $30^{\circ} \mathrm{C}$, this aligns well with

388 the observation that parasitoid wasps avoid flying and have a reduced survival at high

389 temperatures (Dyer and Landis 1996). The positive effect of dewpoint on parasitism indicates

390 that Encarsia parasitoids are more active under humid conditions, which limits the risk of 
dehydration (Sorribas et al. 2012). The variable “year” may have accounted for the different

392 vegetation background in arable fields (fallow in 2007 vs. seedling sorghum in 2008), the

393 weather conditions in 2007 and 2008 prior to the experiment or differences in cropping

394 history in the arable fields. The year of 2007 was characterised by drought, whereas 2008 had

395 more rain. This analysis highlights that both land use and meteorological variables are needed

396 to understand the colonization dynamics of parasitoids in agro-landscapes.

397 In conclusion, our study suggests that remnant vegetation provides important habitats

398 for the conservation of parasitoids that contribute to pest suppression in crops, and that

399 biocontrol services extend beyond $125 \mathrm{~m}$ from remnant vegetation into crops. We also show

400 that this colonization is fast (within three days after the introduction of pests) and recurrent

401 (parasitism occurred at all time periods), but the spatial pattern of crop colonization is

402 scattered across the landscape. Therefore, in practice, it may be necessary to monitor whether

403 or not colonization has occurred before a grower should put his trust in natural enemies for his

404 whitefly control. The likelihood of encountering parasitoids is higher near remnant vegetation

405 than in the field centre, hence for the assessment of presence-absence of parasitoids,

406 monitoring should be concentrated near remnant vegetation-field interfaces. The reliability of

407 biocontrol services in an agricultural landscape is expected to increase as more remnant

408 vegetation is available because the frequency of crop colonization by parasitoids from

409 remnant vegetation is increased.

\section{Acknowledgements}

413 We thank Anna Marcora, Andrew Hulthen, Lynita Howie, Norm Winters, Karen Stanford and

414 Kylie Lukins for field assistance, data collection and species identification, as well as the

415 landholders for their support. This research was financially supported by the Cotton

416 Catchment Communities Cooperative Research Centre and Land and Water Australia. 


\section{References}

418 Millennium Ecosystem Assessment. 2005. Ecosystems and human wellbeing: Synthesis. Island Press, Washington (DC).

Bianchi, F. J. J. A., C. J. H. Booij, and T. Tscharntke. 2006. Sustainable pest regulation in agricultural landscapes: a review on landscape composition, biodiversity and natural pest control. Proceedings of the Royal Society B: Biological Sciences 273:1715-1727.

Bianchi, F. J. J. A., P. W. Goedhart, and J. M. Baveco. 2008. Enhanced pest control in cabbage crops near forest in The Netherlands. Landscape Ecology 23:595-602.

Bianchi, F. J. J. A., N. A. Schellhorn, and S. A. Cunningham. 2012. Habitat functionality for the ecosystem service of pest control: reproduction and feeding sites of pests and natural enemies. Agricultural and Forest Entomology 15:12-23.

Bolker, B. M. 2008. Ecological models and data in R. Princeton University Press.

Burnham, K. P., and D. R. Anderson. 2002. Model selection and multimodel inference : a practical information-theoretic approach. Springer, New York.

Chaplin-Kramer, R., M. E. O'Rourke, E. J. Blitzer, and C. Kremen. 2011. A meta-analysis of crop pest and natural enemy response to landscape complexity. Ecology Letters 14:922-932.

Costamagna, A. C., and D. A. Landis. 2007. Quantifying predation on soybean aphid through direct field observations. Biological Control 42:16-24.

Crawley, M. J. 2007. The R book. Wiley, Chichester.

De Barro P. J., F. Driver, I. D. Naumann, G. M. Clarke, S. Schmidt, and J. Curran 2000. Descriptions of three species of Eretmocerus Haldeman (Hymenoptera: Aphelinidae) parasitising Bemisia tabaci (Gennadius) (Hemiptera: Aleyrodidae) and Trialeurodes vaporariorum (Westwood) (Hemiptera: Aleyrodidae) in Australia based on morphological and molecular data. Australian Journal of Entomology 39: 259-269.

De Barro P. J., S. S. Liu, L. M. Boykin, and A. B. Dinsdale. 2011. Bemisia tabaci: a statement of species status. Annual Review of Entomology 56: 1-19. 
Dyer, L. E., and D. A. Landis. 1996. Effects of habitat, temperature, and sugar availability on longevity of Eriborus terebrans (Hymenoptera: Ichneumonidae). Environmental Entomology 25:1192-1201.

Dyer, L. E., and D. A. Landis. 1997. Influence of noncrop habitats on the distribution of Eriborus terebrans (Hymenoptera: Ichneumonidae) in cornfields. Environmental Entomology 26:924-932.

Ekström, G., and B. Ekbom. 2011. Pest control in agro-ecosystems: an ecological approach. Critical Reviews in Plant Sciences 30:74-94.

Fink, U., and W. Volkl. 1995. The effect of abiotic factors on foraging and oviposition success of the aphid parasitoid, Aphidius rosae. Oecologia 103:371-378.

Gurr, G. M., S. D. Wratten, and W. E. Snyder. 2012. Biodiversity and insect pests: key issues 455 for sustainable management. John Wiley \& Sons.

Kremen, C. 2005. Managing ecosystem services: what do we need to know about their ecology? Ecology Letters 8:468-479.

Kristensen, N. P., P. J. De Barro, and N. A. Schellhorn. 2013. The initial dispersal and spread of an intentional invader at three spatial scales. PloS one $\mathbf{e 6 2 4 0 7 .}$

Landis, D. A., and M. J. Haas. 1992. Influence of landscape structure on abundance and within-field distribution of European corn borer (Lepidoptera: Pyralidae) larval parasitoids in Michigan. Environmental Entomology 21:409-416.

Letourneau, D. K., S. G. Bothwell, and J. O. Stireman. 2012. Perennial habitat fragments, parasitoid diversity and parasitism in ephemeral crops. Journal of Applied Ecology

469 Macfadyen, S., and W. Muller. 2013. Edges in agricultural landscapes: species interactions and movement of natural enemies. PloS one 8:e59659. 
Martin, J. H. 1999. The whitefly fauna of Australia. A taxonomic account and identification guide. CSIRO Entomology Technical Paper No. 38.

Pickett, C. H., and M. J. Pitcairn. 1999. Classical biological control of ash whitefly: factors contributing to its success in California. Biocontrol 44:143-158.

Rauwald, K. S., and A. R. Ives. 2001. Biological control in disturbed agricultural systems and the rapid recovery of parasitoid populations. Ecological Applications 11:1224-1234.

Schellhorn, N. A., F. J. J. A. Bianchi, and C. L. Hsu. 2014. Movement of entomophagous arthropods in agricultural landscapes: links to pest suppression. Annual Review of Entomology 59:559-581.

Schellhorn, N. A., S. MacFadyen, F. J. J. A. Bianchi, D. G. Williams, and M. P. Zalucki. 2008. Managing ecosystem services in broad-acre landscapes: what are the appropriate spatial scales? Australian Journal of Experimental Agriculture 48:15491559.

Sequeira R.V., A. Shields, A. Moore, and P. De Barro. 2009. Inter-seasonal population dynamics and pest status of Bemisia tabaci (Gennadius) biotype B in an Australian cropping system. Bulletin of Entomological Research 99: 325-335.

Sorribas, J., J. van Baaren, and F. Garcia-Marí. 2012. Effects of climate on the introduction, distribution and biotic potential of parasitoids: Applications to biological control of California red scale. Biological Control 62:103-112.

Thies, C., I. Steffan-Dewenter, and T. Tscharntke. 2003. Effects of landscape context on herbivory and parasitism at different spatial scales. Oikos 101:18-25.

Thomas, M. B., S. D. Wratten, and N. W. Sotherton. 1991. Creation of island habitats in farmland to manipulate populations of beneficial arthropods predator densities and emigration. Journal of Applied Ecology 28:906-917.

Thomson, L. J., and A. A. Hoffmann. 2009. Vegetation increases the abundance of natural enemies in vineyards. Biological Control 49:259-269.

Venables, W. N., and B. D. Ripley. 2002. Modern Applied Statistics with S. Fourth Edition. Springer, New York. 
499 Wissinger, S. A. 1997. Cyclic colonization in predictably ephemeral habitats: a template for $500 \quad$ biological control in annual crop systems. Biological Control 10:4-15.

501 Zuur, A. F., E. N. Ieno, N. J. Walker, A. A. Saveliev, and G. M. Smith. 2009. Mixed effects 502 models and extensions in ecology with R. Springer.

503 


\section{$504 \quad$ List of figures}

505 Figure 1: Schematic representation of the spatial design of sentinel plants infested with

506 whitefly nymphs in plots in, near and far from remnant vegetation. Sentinel plants are

507 indicated with the black squares. In each landscape 9 plots were established, 3 plots $(50 \times 75$

$508 \mathrm{~m})$ were set out in patches of remnant vegetation, 3 plots $(100 \times 75 \mathrm{~m})$ in arable fields $25 \mathrm{~m}$

509 from remnant vegetation plots, and 3 plots $(100 \times 75 \mathrm{~m})$ in arable fields that were at least 400

$510 \mathrm{~m}$ from remnant vegetation, for a total of 18 plots (2 landscapes $\mathrm{x} 9$ plots). The exposures

511 were replicated three times in a period of approximately 2 weeks, both in 2007 and in 2008,

512 bringing the number of exposed plants to 2 year x 3 periods $x 2$ landscapes x $(3 \times 12+3 \times 20$

$513+3 \times 20)=1872$.

514 Figure 2: Mean number of whitefly nymphs parasitized per plant ( \pm SEM) in three periods in

5152007 (black marker, solid line) and 2008 (white marker, dotted line) (A), and in plots in, near

516 and far from remnant vegetation in North (black marker, solid line) and South landscape

517 (white marker, dotted line) (B). 


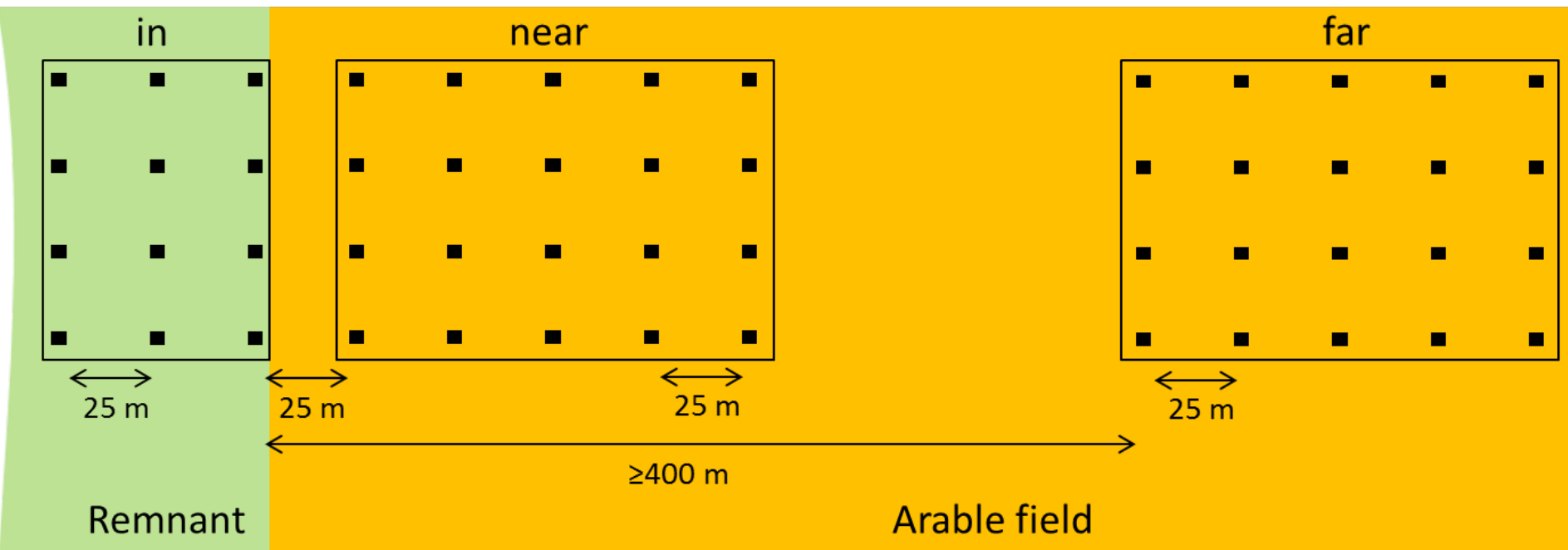

$518 \quad$ Fig. 1 

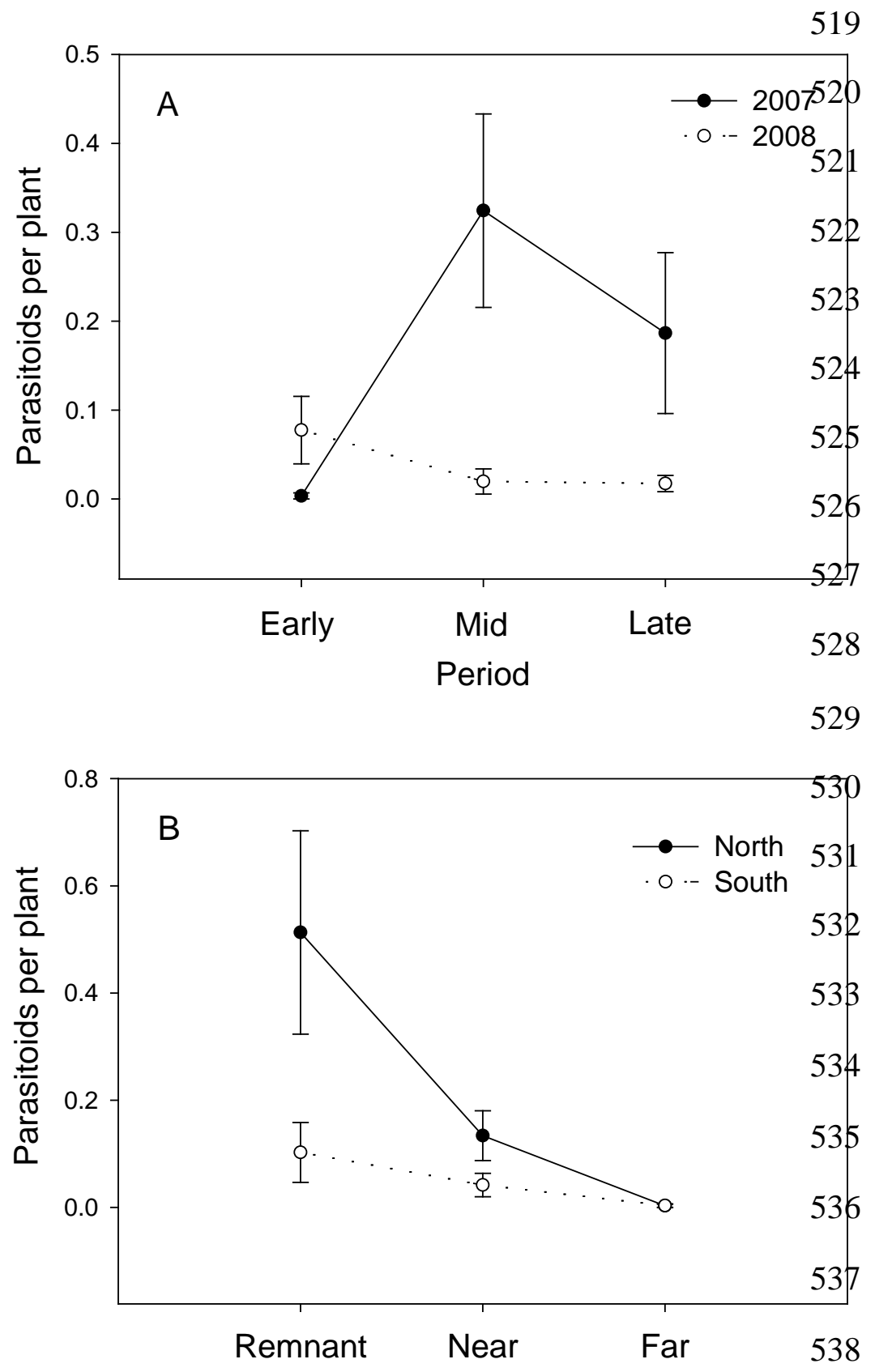

539

$540 \quad$ Fig. 2

541 
542 Table 1: Overview of model selection statistics for models predicting the number of

543 parasitized whitefly nymphs per plant using factorial variables (landscape, period, treatment,

544 year, and the offset variable log-exposure hours). The number of parameters in the model is

545 indicated by df, $\mathrm{AIC}_{\mathrm{c}}$ is the corrected AIC for finite sample sizes, $\Delta \mathrm{AIC}_{\mathrm{c}}$ is the difference in

$546 \quad$ AIC $_{c}$ with the model with the lowest AIC $_{c}$ value, and Akaike weights (Weight) represent the

547 posterior probabilities or "degrees of belief” of the models in the set. Only models with

548 substantial support from the data (i.e. within an $\mathrm{AIC}_{\mathrm{c}}$ range of 6 points from the most

549 parsimonious model) are presented.

550

551 Landsc Period Treat Year Landsc:Treat Period:Year off(lexph) ${ }^{\dagger}$ df AIC $_{c} \quad \Delta$ AICc Weight

552

553

554

555

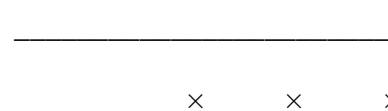

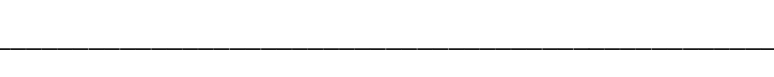

$\begin{array}{lllll}\times & 9 & 554.9 & 0 & 0.385\end{array}$

556

$\times \quad \times \quad \times$

$x$

$\times$

$9 \quad 554.9 \quad 0$

0.379

556

$x \quad x \quad x$

$\times$

$\begin{array}{lll}12 & 557.7 & 2.8\end{array}$

0.095

557

558

$\times$

$\times \quad \times$

$\times$

$\begin{array}{llll}12 & 558.3 & 3.4 & 0.070\end{array}$

559

560

561

${ }^{\dagger}$ offset variable log-exposure hours

562 
563 Table 2: Model estimates and 95\% confidence intervals (on a natural logarithm scale) of the

564 most parsimonious model based on the factors treatment, year, period and the

565 period:year interaction. The model has an AIC of $554.77\left(\mathrm{AIC}_{\mathrm{c}}=554.9\right)$ and uses a

566 negative binominal error distribution with $k=0.0217$ and has an overall mean of

$567 \quad 0.106$.

568

569

Estimate lower 95\% CI upper 95\% CI

570

571 Intercept

$\begin{array}{lll}-3.981 & -7.095 & -1.671\end{array}$

$572 \quad$ Near

$-1.735$

$-2.912$

$-0.664$

573 Far

$-4.716$

$-6.903$

$-2.984$

574 Year 2008

2.302

$-0.149$

5.544

$575 \quad$ Period 2

4.357

2.001

7.592

$576 \quad$ Period 3

3.423

1.037

6.657

577 Year 2008:Period 2

$-5.765$

$-9.418$

$-2.763$

578 Year 2008:Period 3

$-4.418$

$-8.027$

$-1.401$

579 
Table 3: Overview of model selection statistics for models predicting the number of parasitized whitefly nymphs per plant using land use and meteorological variables, and the offset variable log-exposure hours. The number of parameters in the model is indicated by df, AIC $_{c}$ is the corrected AIC for finite sample sizes, $\Delta \mathrm{AIC}_{\mathrm{c}}$ is the difference in $\mathrm{AIC}_{\mathrm{c}}$ with the model with the lowest $\mathrm{AIC}_{\mathrm{c}}$ value, and Akaike weights (Weight) represent the posterior probabilities or "degrees of belief" of the models in the set. Only models with substantial support from the data (i.e. within an AIC $_{c}$ range of 6 points from the most parsimonious model) are presented.

\begin{tabular}{|c|c|c|c|c|c|c|c|c|c|c|c|c|c|c|}
\hline Remnant & Remnant & Remnant & Remnant & Grass & Grass & Temp & Wind & Dewpoint & Year & off(lexph $)^{\dagger}$ & $\mathrm{df}$ & AICc & $\triangle \mathrm{AICc}$ & Weight \\
\hline $0-100 \mathrm{~m}$ & $100-500 \mathrm{~m}$ & $500-1000 \mathrm{~m}$ & $1000-1500 \mathrm{~m}$ & $100-500 \mathrm{~m}$ & $500-1000 \mathrm{~m}$ & & & & & & & & & \\
\hline$\times$ & $x$ & $x$ & $x$ & $x$ & $x$ & $\times$ & $x$ & $x$ & $x$ & & 12 & 523.7 & 0 & 0.328 \\
\hline$\times$ & $x$ & $x$ & $x$ & $x$ & $x$ & $x$ & $x$ & $x$ & $x$ & $\times$ & 12 & 523.8 & 0.1 & 0.313 \\
\hline$x$ & $x$ & $x$ & $x$ & $x$ & & $x$ & $x$ & $x$ & $x$ & $x$ & 11 & 525.2 & 1.5 & 0.150 \\
\hline$\times$ & $x$ & $x$ & $x$ & $x$ & & $\times$ & $x$ & $x$ & $x$ & & 11 & 525.7 & 2.0 & 0.118 \\
\hline$x$ & $x$ & $x$ & & $x$ & & $x$ & $x$ & $x$ & $x$ & $x$ & 10 & 527.5 & 3.8 & 0.047 \\
\hline$x$ & $x$ & $x$ & & $x$ & $x$ & $\times$ & $x$ & $x$ & $x$ & $\times$ & 11 & 527.7 & 4.0 & 0.038 \\
\hline$x$ & $x$ & $x$ & & $x$ & & $x$ & $x$ & $x$ & $x$ & & 10 & 527.9 & 4.2 & 0.036 \\
\hline$x$ & $x$ & $x$ & & $x$ & $x$ & & $x$ & $x$ & $x$ & $x$ & 11 & 528.6 & 4.9 & 0.025 \\
\hline
\end{tabular}


${ }^{\dagger}$ offset variable log-exposure hours 
Table 4: Model estimates and 95\% confidence intervals (on a natural logarithm scale) of the most parsimonious model based on land use and meteorological variables. The model has an AIC of $523.49\left(\mathrm{AIC}_{\mathrm{c}}=523.7\right)$ and a negative binominal error distribution with $k=0.0499$.

\begin{tabular}{llll}
\hline & Estimate & lower 95\% CI & upper 95\% CI \\
& & & \\
\hline Intercept & -5.249 & -12.087 & 1.280 \\
Remnant vegetation 0-100 m & 2.412 & 1.562 & 3.517 \\
Remnant vegetation 100-500 m & 0.276 & 0.149 & 0.461 \\
Remnant vegetation 500-1000 m & 0.134 & 0.027 & 0.259 \\
Remnant vegetation 1000-1500 m & -0.177 & -0.362 & -0.039 \\
Grassland 100-500m & -0.482 & -1.020 & -0.162 \\
Grassland 500-1000m & 0.163 & 0.005 & 0.364 \\
Wind & 0.758 & 0.409 & 1.177 \\
Temperature & -0.748 & -1.304 & -0.239 \\
Dew point temperature & 0.814 & 0.433 & 1.249 \\
Year 2008 & -1.288 & -2.308 & -0.273 \\
& & & \\
\hline
\end{tabular}




\section{Appendix 1}

Presence/absence of parasitism at the plot level in plots in, near and far from remnant vegetation. There are 3 spatial replicates $\times 2$ landscapes $\times 3$ periods $\times 2$ years $=36$ cases for each distance treatment. A “+” indicates that parasitism was detected, while “-” indicates that no parasitism was observed. These contingency tables are used to test the association between parasitism in plots in remnant vegetation and plots near (A) or far (B) in arable fields using $\chi^{2}$ test of independence with 1 degree of freedom. The null-hypothesis that presence of parasitism in plots in and near remnant vegetation is independent was not rejected $\left(\chi^{2}=0.486\right.$, $\mathrm{df}=1, \mathrm{P}=0.486$ ). Similarly, there was no support for the hypothesis that the incidence of parasitism in plots in and far from remnant vegetation are dependent $\left(\chi^{2}=0, d f=1, P=1\right)$.

\begin{tabular}{cl|ll|l} 
& \multicolumn{4}{c}{ Near } \\
Remnant & + & - & Total \\
\cline { 2 - 5 } & + & 3 & 10 & 13 \\
& - & 2 & 21 & 23 \\
\cline { 2 - 5 } & Total & 5 & 31 & 36
\end{tabular}

\begin{tabular}{cl|ll|l} 
& \multicolumn{3}{|l}{ Far } & \\
\multirow{3}{*}{ Remnant } & + & - & \multicolumn{1}{l}{ Total } \\
\cline { 2 - 5 } & + & 1 & 12 & 13 \\
& - & 1 & 22 & 23 \\
\cline { 2 - 5 } & Total & 2 & 34 & 36
\end{tabular}

A 


\section{Appendix 2}

Number of parasitized whiteflies per year, landscape, treatment and time period. The numbers are pooled across the 3 spatial replicate plots in each landscape. Treatments are described by the spatial relationship with remnant vegetation.

\begin{tabular}{|c|c|c|c|c|c|c|}
\hline \multirow[t]{2}{*}{ year } & \multirow[t]{2}{*}{ Landscape } & \multirow[t]{2}{*}{ Treatment } & \multicolumn{4}{|c|}{ Period } \\
\hline & & & 1 & 2 & 3 & Total \\
\hline \multirow[t]{6}{*}{2007} & North & In & 0 & 53 & 37 & 90 \\
\hline & & Near & 0 & 41 & 0 & 41 \\
\hline & & Far & 0 & 1 & 0 & 1 \\
\hline & South & In & 0 & 0 & 0 & $\mathbf{0}$ \\
\hline & & Near & 0 & 1 & 13 & 14 \\
\hline & & Far & 1 & 0 & 0 & 1 \\
\hline \multirow[t]{6}{*}{2008} & North & In & 4 & 3 & 2 & 9 \\
\hline & & Near & 2 & 0 & 2 & 4 \\
\hline & & Far & 0 & 0 & 0 & $\mathbf{0}$ \\
\hline & South & In & 17 & 2 & 1 & 20 \\
\hline & & Near & 0 & 0 & 0 & $\mathbf{0}$ \\
\hline & & Far & 0 & 0 & 0 & $\mathbf{0}$ \\
\hline
\end{tabular}

